\title{
Reference evapotranspiration change and its sensitivity to climate variables in southwest China
}

\author{
Tiegang Liu ${ }^{1}$ Longguo $\mathrm{Li}^{1} \cdot \mathrm{Jianbin}_{\mathrm{Lai}^{2}}{ }^{2}$ Chao Liu ${ }^{1}$ Wenhua Zhuang ${ }^{1}$
}

Received: 1 December 2014 / Accepted: 1 June 2015 / Published online: 10 June 2015

(C) Springer-Verlag Wien 2015

\begin{abstract}
Reference evapotranspiration $\left(\mathrm{ET}_{0}\right)$ is the key factor for hydrologic water balance, irrigation scheduling, and water resources planning. Based on Food and Agriculture Organization (FAO) Penman-Monteith method and the climate variables of 57 meteorological stations from 1960 to 2010 in southwest China, the spatial and temporal distributions of $\mathrm{ET}_{0}$ were analyzed by using Mann-Kendall test and Sen's slope estimator. Sensitivity coefficient was used to analyze the sensitivities of $\mathrm{ET}_{0}$ to four climate variables, and the key climate variables attributed to $\mathrm{ET}_{0}$ change were determined. Result showed that there was a slight downward trend of $\mathrm{ET}_{0}$ from 1960 to 2010 and spatially increasing trend from northeast to southwest in annual time scale. Results also showed that $\mathrm{ET}_{0}$ had relatively higher sensitivity to wind speed and mean air temperature, and wind speed was the dominant variable for change of $\mathrm{ET}_{0}$ in southwest China. The inverse relationship between increasing air temperature and decreasing evaporation, "evaporation paradox," existed in southwest China, and the negative contribution of wind speed to the changes of $\mathrm{ET}_{0}$ offset the positive contribution of air temperature.
\end{abstract}

Chao Liu

liuchaohydro@163.com

1 State Key Laboratory of Hydraulics and Mountain River Engineering, College of Water Resource and Hydropower, Sichuan University, No.24 South Section 1, Yihuan Road, Chengdu 610065, China

2 Yucheng Comprehensive Experimental Station, Key Laboratory of Ecosystem Network Observation and Modeling, Institute of Geographic Sciences and Natural Resources Research, Chinese Academy of Sciences (CAS), Beijing 100101, China

\section{Introduction}

Evapotranspiration (ET) is one of the most important components of hydrologic cycle (Sabziparvar et al. 2010) and also is one of the key input factors for hydrological model. As ET is influenced by many factors including climate factors, crop factors, management, and environmental conditions, the estimation of actual ET over many regions where spatial and temporal variability exist in these factors is challenging (Tabari et al. 2012), reference ET (ET $)$ under hypothetical crop and conditions is estimated as an alternative method for the study of hydrologic water balance, irrigation scheduling, and water resources planning (Dinpashoh 2006). $\mathrm{ET}_{0}$ is influenced by the changes of climate variables such as air temperature, relative humidity, and wind speed, which has a nonlinear complex relationship with many of the parameters, and therefore the changes of the parameters on $\mathrm{ET}_{0}$ is difficult to understand (Dinpashoh et al. 2011). The accurate estimation of reference evapotranspiration $\left(\mathrm{ET}_{0}\right)$ and its spatial and temporal analyses are significant for realizing the influences of climate change on hydrologic cycle.

Some researchers found there were decreasing trends in $\mathrm{ET}_{0}$ or pan evaporation $\left(\mathrm{ET}_{\mathrm{pan}}\right)$ in the different regions throughout the world including Canadian, the USA, Australia, and India (Gan 1998; Lawrimore and Peterson 2000; Roderick and Farquhar 2004; Bandyopadhyay et al. 2009; Jhajhariam et al. 2011). On the other hand, $\mathrm{ET}_{0}$ has increasing trends in some regions (Hess 1998; Talaee et al. 2014). For China, the general decreasing trends of $\mathrm{ET}_{0}$ were reported, although the air temperature had increasing trends (Thomas 2000; Gao et al. 2006). The inverse relationship between increasing air temperature and decreasing evaporation has been known as the "evaporation paradox" (Roderick and Farquhar 2002). Cong et al. (2009) reported that "pan evaporation paradox" existed in China as a whole, but it was not spatially 
universal. Liu et al. (2010) reported that sunshine duration and maximum air temperature were the most important climate variables to influence the changes of $\mathrm{ET}_{\mathrm{pan}}$ for the whole China.

The southwest region of China is an important grainproducing area for China and also is characterized by unique climate and complicated topography. The change of ET in this area has important influences on the water resources and agricultural production of the local area. Xu et al. (2006) found that the maximal annual $\mathrm{ET}_{0}$ occurred in the southwest of the upper region for Yangtze River basin, which was mainly located in Sichuan. However, there was little intensive study on the spatial and temporal changes in the reference evapotranspiration in southwest China. In this paper, annual $\mathrm{ET}_{0}$ were estimated for southwest China by using FAO-56 Penman-Monteith method, and annual $\mathrm{ET}_{0}$ trends for 1960-2010 were analyzed by using the Mann-Kendall test and Sen's slope estimator. Moreover, the sensitivity of $\mathrm{ET}_{0}$ to regular climate observation variables in climate station (mean air temperature, relative humidity, wind speed, and sunshine duration) and their contributions to the changes of annual $\mathrm{ET}_{0}$ were investigated for southwest China.

\section{Data and methods}

\subsection{Study area and data}

In this paper, southwest China encompasses Sichuan Province, Guizhou Province, Yunnan Province, and Chongqing City, which has an area of $113.8 \times 10^{4} \mathrm{~km}^{2}$. It is approximately between $21.2^{\circ} \mathrm{N}-34.4^{\circ} \mathrm{N}$ latitudes and $97.4^{\circ} \mathrm{E}-110.2^{\circ} \mathrm{E}$ longitudes. The area is dominated by subtropical monsoon climate with the characteristics of dry winter and wet summer. The average annual precipitation is more than $900 \mathrm{~mm}$, while its inter-annual and annual distributions are not even (Wang et al. 2010). There are mainly four typical landforms: plateau, mountain, hill, and plain.

Meteorological data from 57 national meteorological observatory stations provided by the National Meteorological Information Centre of China (NMIC) of the China Meteorological Administration (CMA) including monthly observations of maximum, minimum, and mean air temperature $\left({ }^{\circ} \mathrm{C}\right)$, relative humidity $(\%)$, wind speed at $10 \mathrm{~m}$ height $(\mathrm{m} / \mathrm{s})$, sunshine duration $(\mathrm{h})$, and atmospheric pressure $(\mathrm{kPa})$ for the period of 1960-2010 was used to calculate $\mathrm{ET}_{0}$ of the study area. The location and distribution of these meteorological stations in the study area are showed in Table 1 and Fig. 1. The quality of meteorological data was examined, and no apparent error was found. Missing monthly data are about $0.47 \%$ as an average for the 57 stations, and were supplemented by the median meteorological data from three neighboring stations (Wang et al. 2012).

\subsection{Methods}

The monthly reference evapotranspiration $\mathrm{ET}_{0}$ was calculated by using Food and Agriculture Organization (FAO) PenmanMonteith method (Allen et al. 1998).

$\mathrm{ET}_{0}=\frac{0.408 \Delta\left(R_{\mathrm{n}}-G\right)+\gamma \frac{900}{T+273} \mu_{2}\left(e_{\mathrm{n}}-e_{\mathrm{a}}\right)}{\Delta+\gamma\left(1+0.34 \mu_{2}\right)}$

where $G$ is the soil heat flux density $\left(\mathrm{MJ} /\left(\mathrm{m}^{2}\right.\right.$ day $\left.)\right), T$ is the mean air temperature at $2 \mathrm{~m}$ height $\left({ }^{\circ} \mathrm{C}\right), u_{2}$ is the wind speed at $2 \mathrm{~m}$ height $(\mathrm{m} / \mathrm{s}), e_{\mathrm{n}}$ is the saturation vapor pressure $(\mathrm{kPa}), e_{\mathrm{a}}$ is the actual vapor pressure $(\mathrm{kPa}), e_{\mathrm{n}}-e_{\mathrm{a}}$ is the saturation vapor pressure deficit $(\mathrm{kPa}), \Delta$ is the slope vapor pressure curve $\left(\mathrm{kPa} /{ }^{\circ} \mathrm{C}\right), \gamma$ is the psychrometric constant $\left(\mathrm{kPa} /{ }^{\circ} \mathrm{C}\right), R_{\mathrm{n}}$ is the net radiation at the crop surface $\left(\mathrm{MJ} /\left(\mathrm{m}^{2}\right.\right.$ day $\left.)\right)$, which is the difference between net shortwave radiation $\left(R_{\mathrm{ns}}\right)$ and net longwave radiation $\left(R_{\mathrm{nl}}\right) \cdot R_{\mathrm{ns}}$ is calculated as

$R_{\mathrm{ns}}=(1-\lambda) R_{\mathrm{s}}$

where $R_{\mathrm{S}}$ is surface solar radiation $\left(\mathrm{MJ} /\left(\mathrm{m}^{2}\right.\right.$ day $\left.)\right)$ and $\lambda$ $(=0.23)$ is the albedo of the reference grassland. $R_{\mathrm{S}}$ can be calculated from sunshine duration $(n)$ :

$R_{\mathrm{s}}=\left(a_{\mathrm{s}}+b_{\mathrm{s}} \frac{n}{N}\right) R_{\mathrm{a}}$

where $N$ is the maximum possible sunshine duration (h), $n / N$ is the relative sunshine duration, $R_{\mathrm{a}}$ is the extraterrestrial radiation $\left(\mathrm{MJ} /\left(\mathrm{m}^{2}\right.\right.$ day $\left.)\right)$, and $a_{\mathrm{s}}$ and $b_{\mathrm{s}}$ are regression constants and are set to be 0.25 and 0.5 respectively. $R_{\mathrm{a}}$ is calculated as

$R_{\mathrm{a}}=\frac{24(60)}{\pi} G_{\mathrm{sc}} d_{\mathrm{r}}\left[\omega_{s} \sin (\phi) \sin (\delta)+\cos (\phi) \cos (\delta) \sin \left(\omega_{\mathrm{s}}\right)\right]$

where $G_{\mathrm{sc}}$ is the solar constant $\left(=0.0820 \mathrm{MJ} /\left(\mathrm{m}^{2}\right.\right.$ day $\left.)\right), d_{\mathrm{r}}$ is inverse relative distance Earth-Sun, $\omega_{\mathrm{s}}$ is the sunset hour angle (rad), $\varphi$ is the latitude (rad), $\delta$ is the solar declination (rad).

$R_{\mathrm{nl}}$ is calculated as

$R_{\mathrm{nl}}=\sigma\left[\frac{T_{\mathrm{max}, \mathrm{K}}{ }^{4}+T_{\min , \mathrm{K}}}{2}\right]\left(0.34-0.14 \sqrt{e_{\mathrm{a}}}\right)\left(1.35 \frac{R_{\mathrm{s}}}{R_{\mathrm{so}}}-0.35\right)$

where $\sigma$ is the Stefan-Bolzmann constant $\left(=4.903 \times 10^{-9} \mathrm{MJ} /\right.$ $\left(\mathrm{K}^{4} \mathrm{~m}^{2}\right.$ day)), $T_{\max , \mathrm{K}}$ is the maximum absolute temperature 
Table 1 Geospatial information of the meteorological stations in the study area

\begin{tabular}{|c|c|c|c|c|c|c|c|c|c|}
\hline No. & Station & Latitude $\left({ }^{\circ} \mathrm{N}\right)$ & Longitude $\left({ }^{\circ} \mathrm{E}\right)$ & Elevation (m) & No. & Station & Latitude $\left({ }^{\circ} \mathrm{N}\right)$ & Longitude $\left({ }^{\circ} \mathrm{E}\right)$ & Elevation (m) \\
\hline 1 & Anshun & 26.25 & 105.93 & 1392.9 & 30 & Lancang & 22.57 & 99.93 & 1054.4 \\
\hline 2 & Baoshan & 25.12 & 99.18 & 1653.5 & 31 & Langzhong & 31.58 & 105.97 & 385.4 \\
\hline 3 & Bazhong & 31.87 & 106.78 & 417.7 & 32 & Leibo & 28.28 & 103.57 & 253.9 \\
\hline 4 & Bijie & 27.3 & 105.29 & 1510.6 & 33 & Leshan & 29.57 & 103.75 & 422.1 \\
\hline 5 & Chuxiong & 25.02 & 101.54 & 1772.0 & 34 & Liangping & 30.7 & 107.8 & 459.4 \\
\hline 6 & Dali & 25.70 & 100.20 & 1990.5 & 35 & Lijiang & 26.87 & 100.22 & 2394.4 \\
\hline 7 & Daocheng & 29.05 & 100.31 & 872.8 & 36 & Lincang & 23.95 & 100.22 & 1464.4 \\
\hline 8 & Daofu & 30.98 & 101.13 & 2597.2 & 37 & Luodian & 25.43 & 106.77 & 441.5 \\
\hline 9 & Daxian & 31.20 & 107.51 & 344.9 & 38 & Luxi & 24.53 & 103.77 & 1705.1 \\
\hline 10 & Dege & 31.80 & 98.60 & 818.4 & 39 & Maerkang & 31.9 & 102.24 & 2665.9 \\
\hline 11 & Deqin & 28.48 & 98.93 & 3319.0 & 40 & Meitan & 27.77 & 107.47 & 792.8 \\
\hline 12 & Dujiangyan & 30.98 & 103.68 & 706.7 & 41 & Mengla & 21.48 & 101.57 & 633.2 \\
\hline 13 & Dushan & 25.83 & 107.56 & 1013.3 & 42 & Mengzi & 23.38 & 103.39 & 1301.7 \\
\hline 14 & Emeishan & 29.52 & 103.35 & 3047.4 & 43 & Mianyang & 31.47 & 104.69 & 472.3 \\
\hline 15 & Fengjie & 31.05 & 109.51 & 607.3 & 44 & Muli & 27.93 & 101.27 & 2427.3 \\
\hline 16 & Ganzi & 31.62 & 100.01 & 3393.5 & 45 & Nanchong & 30.78 & 106.11 & 309.7 \\
\hline 17 & Gongshan & 27.75 & 98.68 & 1583.3 & 46 & Neijiang & 29.58 & 105.06 & 309.7 \\
\hline 18 & Guangyuan & 32.43 & 105.87 & 492.4 & 47 & Panxian & 25.78 & 104.63 & 1515.2 \\
\hline 19 & Guiyang & 26.58 & 106.73 & 1074.3 & 48 & Pingbian & 22.98 & 103.69 & 1412.1 \\
\hline 20 & Huaping & 26.63 & 101.28 & 1242.0 & 49 & Qianxi & 27.03 & 106.02 & 1252.5 \\
\hline 21 & Huili & 26.65 & 102.27 & 1788.6 & 50 & Rongjiang & 25.97 & 108.54 & 287.4 \\
\hline 22 & Huize & 26.42 & 103.30 & 2113.4 & 51 & Ruili & 24.02 & 97.86 & 776.4 \\
\hline 23 & Jiangcheng & 22.58 & 101.87 & 1120.8 & 52 & Ruoergai & 33.58 & 102.97 & 3441.1 \\
\hline 24 & Jingdong & 24.47 & 100.88 & 1163.5 & 53 & Sansui & 26.97 & 108.67 & 611.0 \\
\hline 25 & Jinghong & 22.00 & 100.82 & 553.6 & 54 & Shapingba & 29.58 & 106.47 & 259.1 \\
\hline 26 & Jiulong & 29.00 & 101.52 & 2993.7 & 55 & Simao & 22.67 & 101.41 & 1302.9 \\
\hline 27 & Kaili & 26.60 & 108.00 & 722.6 & 56 & Sinan & 27.95 & 108.26 & 417.7 \\
\hline 28 & Kangding & 30.05 & 101.98 & 2615.5 & 57 & Songpan & 32.65 & 103.58 & 2852.1 \\
\hline 29 & Kunming & 25.02 & 102.70 & 1896.8 & & & & & \\
\hline
\end{tabular}

during the 24-h period $\left(\mathrm{K}={ }^{\circ} \mathrm{C}+273.16\right), T_{\min , \mathrm{K}}$ is the minimum absolute temperature during the $24-\mathrm{h}$ period $\left(\mathrm{K}={ }^{\circ} \mathrm{C}+\right.$ 273.16), $e_{\mathrm{a}}$ is the actual vapor pressure ( $\left.\mathrm{kPa}\right)$, and $R_{\mathrm{so}}$ is the clear-sky radiation $\left(\mathrm{MJ} /\left(\mathrm{m}^{2}\right.\right.$ day $\left.)\right)$.

In this study, nonparametric statistical analyses, MannKendall (Mann 1945; Kendall 1975) and Sen's slope estimator (Sen 1968), $\beta$, were used to test the magnitude of the trend in $\mathrm{ET}_{0}$. Mann-Kendall method is a rank-based nonparametric method for assessing the significance of trends. As MannKendall method does not need any distribution assumption for the data, it is recommended by World Meteorological Organization and has been widely used to assess the significance of trends in hydro-meteorological time series (Wang et al. 2012; Tabari et al. 2012). A statistic $S$ is calculated as follows:

$S=\sum_{i=1}^{n-1} \sum_{j=i+1}^{n} \operatorname{sgn}\left(x_{j}-x_{i}\right)$ where $n$ is the number of the observations, the $x_{j}$ are the $j$ th observation in the data set, and

$\operatorname{sgn}(\theta)= \begin{cases}1 & \left(x_{j}-x_{i}\right)>0 \\ 0 & \left(x_{j}-x_{i}\right)=0 \\ -1 & \left(x_{j}-x_{i}\right)<0\end{cases}$

Under the assumption that the data are independent and identically distributed, the mean and the variance of the $S$ statistic are given as follows (Mann 1945; Kendall 1975):

$E(S)=0$

$\operatorname{Var}(S)=\frac{n(n-1)(2 n+5)-\sum_{i=1}^{m} t_{i}\left(t_{i}-1\right)\left(2 t_{i}+5\right)}{18}$ 


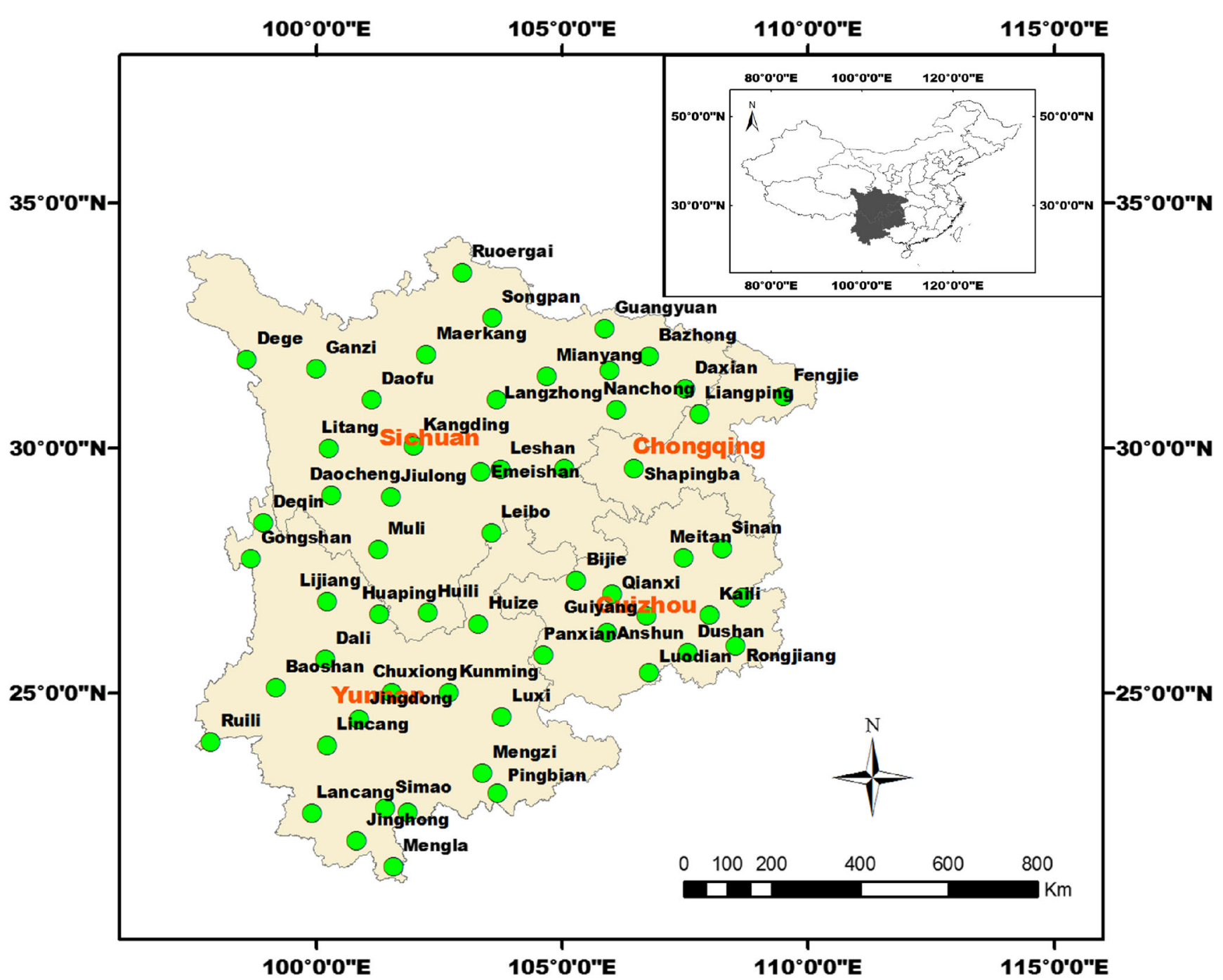

Fig. 1 Distribution of the meteorological stations in the study area

where $t_{i}$ is the number of ties of extent $m$. The standardized test statistic $Z$ is calculated as follows:

$Z=\left\{\begin{array}{lc}\frac{S-1}{\sqrt{\operatorname{Var}(S)}} & S>0 \\ 0 & S=0 \\ \frac{S+1}{\sqrt{\operatorname{Var}(S)}} & S<0\end{array}\right.$

When $|Z| \geq Z_{1-\alpha / 2}$, the hypothesis that there is no trend will be rejected at the significance level of $\alpha$.

Sen's slope estimator is a slope-based method and closely related to Mann-Kendall test (Tabari et al. 2012). The Theil-Sen's estimator, $\beta$, is calculated as follows:

$\beta=\operatorname{Median}\left(\frac{x_{j}-x_{l}}{j-l}\right) \quad \forall 1<l<j$ where $x_{j}$ and $x_{l}$ are the time-series data. A positive $\beta$ indicates an "increasing trend," while a negative $\beta$ indicates a "decreasing trend."

Sensitive coefficient was defined as the ratio of change rate of $\mathrm{ET}_{0}$ and change rate of climate variable (McCuen 1974; Liu et al. 2012)

$S_{x}=\lim \left(\frac{\Delta \mathrm{ET}_{0} / \mathrm{ET}_{0}}{\Delta x / x}\right)=\frac{\partial \mathrm{ET}_{0}}{\partial x} \cdot \frac{x}{\mathrm{ET}_{0}}$

where $\mathrm{ET}_{0}$ is the reference evapotranspiration ( $\mathrm{mm} /$ day), $x$ is the climate variable, $S_{x}$ is the sensitivity coefficient of $\mathrm{ET}_{0}$ which is related to $x$. A positive $S_{x}$ for a climate variable indicates that $\mathrm{ET}_{0}$ will increase with the increasing climate variable (Liu et al. 2012). 
Fig. 2 Spatial distribution of annual $\mathrm{ET}_{0}$ for Southwest China

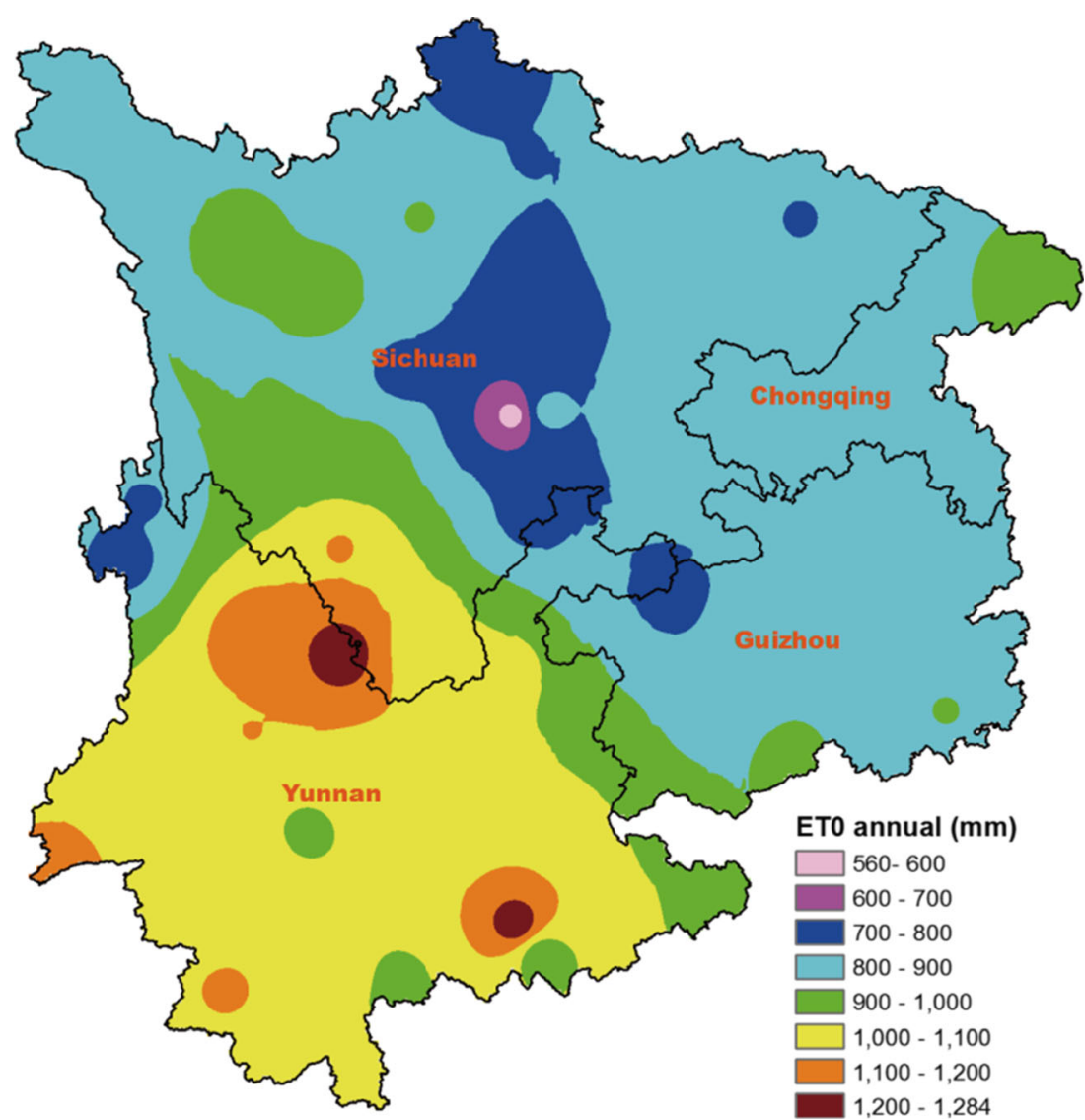

The relative contribution of climate variables to the change of $\mathrm{ET}_{0}$ at annual scale was estimated by using the approach of Yin et al. (2010).

$C_{x}=S_{x} \cdot \mathrm{RC}_{x}$

$\mathrm{RC}_{x}=\frac{n \cdot \beta_{x}}{\left|\mathrm{av}_{x}\right|} \times 100 \%$

where $C_{x}$ is contribution rate of climate variable $x$ to $\mathrm{ET}_{0}, n$ is the number of observations, $\mathrm{RC}_{x}$ is the relative change of $x$ to absolute average value $\left(\left|\mathrm{av}_{x}\right|\right)$ in observation period, $\beta_{x}$ is the magnitude of the trend of climate variable $x$ in observation period, expressed by Sen's slope estimator.

\section{Results}

\subsection{Spatial distribution of annual $\mathrm{ET}_{0}$}

The spatial distribution of annual $\mathrm{ET}_{0}$ for southwest China is showed in Fig. 2. The mean annual $\mathrm{ET}_{0}$ in the whole study area, which was calculated by inverse distance weight interpolating (IDW), was $918.59 \mathrm{~mm} /$ year during the period from 1960 to 2010 . It can be seen that the mean annual $\mathrm{ET}_{0}$ ranged from 560 to $1284 \mathrm{~mm} /$ year, and generally had an increasing trend from the northeast to southwest. In most of Sichuan, Guizhou, and Chongqing, the mean annual $\mathrm{ET}_{0}$ were less than $900 \mathrm{~mm} /$ year. The largest value was found in Huaping station located in north region of Yunnan (1284.12 mm/year), while Emeishan station, which was in southeast of Sichuan, had the lowest one $(558.66 \mathrm{~mm} /$ year $)$.

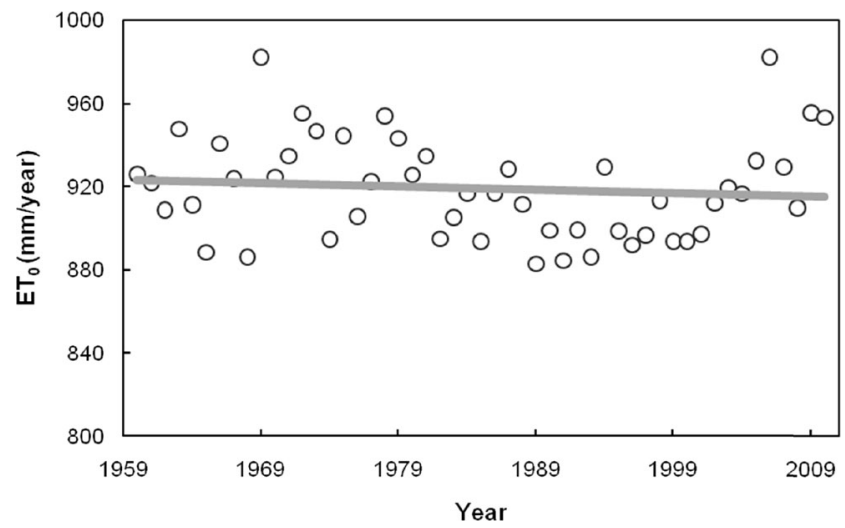

Fig. 3 The time series of annual $\mathrm{ET}_{0}$ for the whole study area from 1960 to 2010 


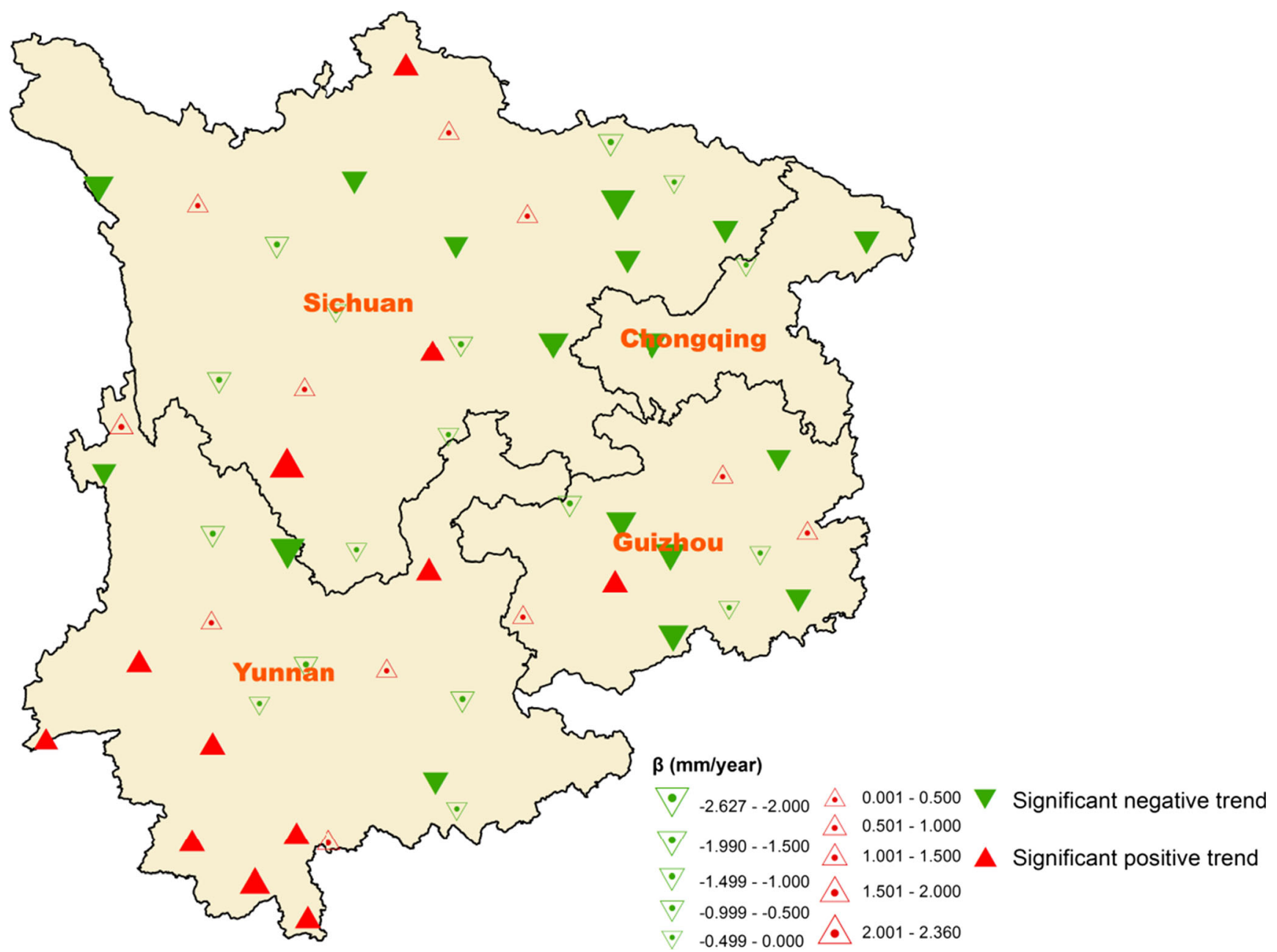

Fig. 4 Trend slopes $(\beta)$ and MK test statistics ( $Z$ at the $95 \%$ confidence level) of annual ET0 from 1960 to 2010 . Red upward and green downward open triangles with a point in center indicate increasing and

\subsection{Trends of annual $\mathbf{E T}_{\mathbf{0}}$}

The time series of annual $\mathrm{ET}_{0}$ from 1960 to 2010 for the whole study area are showed in Fig. 3. Mann-Kendall test showed that $\mathrm{ET}_{0}$ had a negative trend which was not significant at $95 \%$ confidence level $(Z=-0.80)$. Sen's slope estimator $(\beta)$ was calculated to identify the slope of the trend line of annual $\mathrm{ET}_{0}$. For the whole study area, $\mathrm{ET}_{0}$ had a downward trend with $0.22 \mathrm{~mm} /$ year.

Figure 4 shows the trend slopes $(\beta)$ and MK test statistics $(Z)$ of annual $\mathrm{ET}_{0}$ from 1960 to 2010 . Among 57 stations, there were 23 stations which had positive trends in annual $\mathrm{ET}_{0}$, while the other stations showed negative trends. In the stations showing positive trends, 12 stations had significant increasing trends at the $95 \%$ confidence level, which mainly distributed in the southwest of Yunnan. Seventeen stations showed significant decreasing trends at the $95 \%$ confidence level, which were mainly distributed in Guizhou and the northeast of Sichuan. In the decreasing tendencies, respectively. Solid upward and downward triangles show significant increasing and decreasing significant trend at $95 \%$, respectively

stations with positive trends, the annual $\mathrm{ET}_{0}$ increased from 0 to $2.36 \mathrm{~mm} /$ year, in which Muli station of Sichuan had the largest positive trend $(\beta=2.354 \mathrm{~mm} /$ year $)$ and was statistically significant at $99 \%$ confidence level $(Z=4.14)$, and Ganzi station, which was in northwest of Sichuan, had the smallest positive trend $(\beta=0.023 \mathrm{~mm} /$ year). For the stations with negative trends, the values of $\beta$ changed among -2.627 to $0 \mathrm{~mm} /$ year. Huaping station in Yunnan presented the largest decreasing trend $(\beta=-2.627 \mathrm{~mm} /$ year), which was also statistically significant at $99 \%$ confidence level $(Z=-3.22)$.

\subsection{Spatial distribution of the sensitivity coefficients}

For the whole study area, the sensitivity coefficient was the maximal for wind speed (0.293), followed by air temperature $(0.205)$, relative humidity $(-0.037)$, and sunshine duration (0.013). Figure 5 shows the spatial distribution of the sensitivity coefficients of annual $\mathrm{ET}_{0}$ for climate 

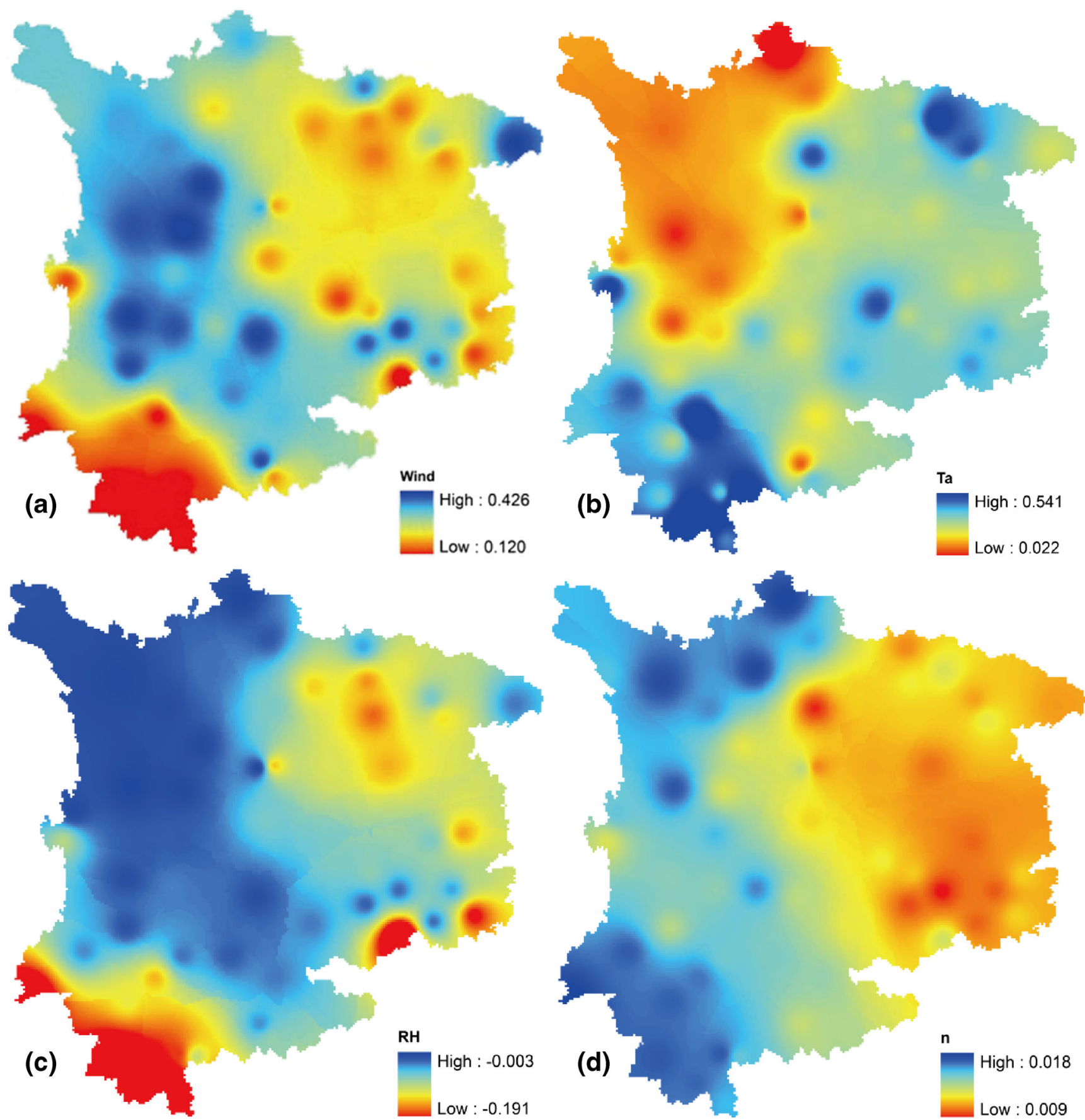

Fig. 5 Spatial distributions of sensitivity coefficient of ET0 for climate variables. a wind speed at $2 \mathrm{~m}$ height $(\mathrm{m} / \mathrm{s})$ (wind); $\mathbf{b}$ mean air temperature at $2 \mathrm{~m}$ height $\left({ }^{\circ} \mathrm{C}\right)(\mathrm{Ta})$; c relative humidity $(\%)(\mathrm{RH})$; d sunshine duration $(n)$

variables. The coefficients for mean wind speed ranged from 0.120 to 0.426 (Fig. 5a), which were higher in the west of Sichuan and north of Yunnan, while lower in the southwest of Yunnan. In most part of Chongqing and Guizhou, the sensitivity of $\mathrm{ET}_{0}$ to mean wind speed was relatively average. The sensitivity coefficients for mean air temperature had the widest range among all climate variables, which ranged from 0.022 to 0.541 (Fig. 5b). The low values were mainly distributed in the west part of
Sichuan Province, where the elevation was relatively higher, and the high values were mainly distributed in the southeast part of Yunnan Province. For relative humidity, sensitivity coefficients were negative for all study area, ranging from -0.191 to -0.003 (Fig. $5 \mathrm{c}$ ). It means that $\mathrm{ET}_{0}$ decreased with the increase of relative humidity. Moreover, the high value area was mainly distributed in the west part of Sichuan and north part of Yunnan, while the southwest part of Yunnan had the lower values. $\mathrm{ET}_{0}$ 
Fig. 6 Contribution rates of climate variables to $\mathrm{ET}_{0}$

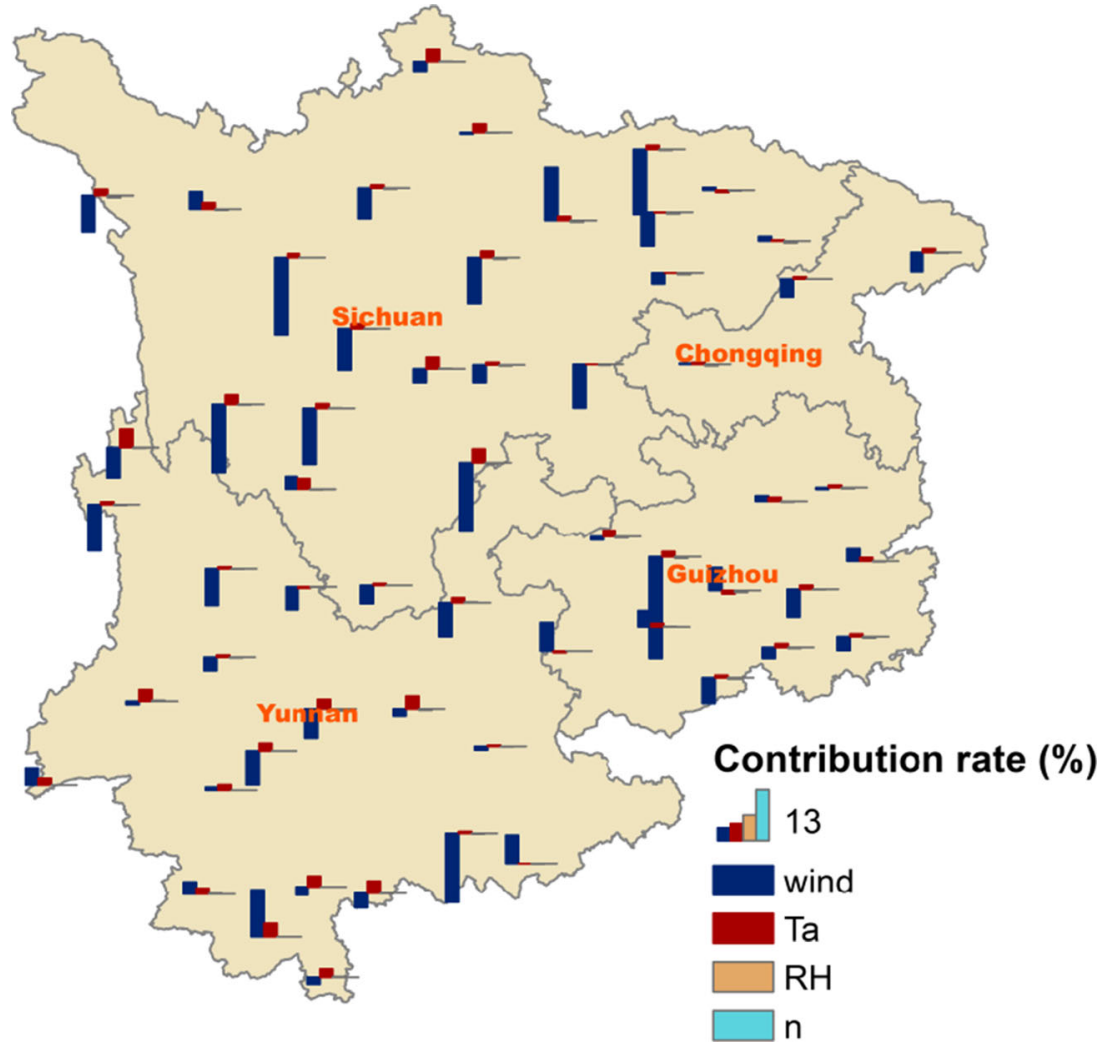

generally had the higher sensitivity to sunshine duration in the northwest of Sichuan and southwest of Yunnan, while was relatively insensitive in Chongqing and Guizhou (Fig. 5d).

In this paper, the results showed that wind speed was the most sensitive factor in southwest China. The similar finding was reported in the other regions in China, such as Loess Plateau Region (Zhao et al. 2014). However, for China as a whole, relative humidity was found to be the most sensitive for $\mathrm{ET}_{0}$ (Yin et al. 2010). Relative humidity was also the most sensitive variable in the Yellow River basin (Shan et al. 2015) and Wei River basin (Zuo et al. 2012). Ye et al. (2014) reported sunshine duration was the most sensitive factor in Poyang Lake catchment. It can be seen that
$\mathrm{ET}_{0}$ has different responses to climate factors in different regions and climate conditions.

\subsection{Contribution rates of climate variables}

Contribution rates of five climate variables to $\mathrm{ET}_{0}$ were calculated in annual scale (Fig. 6 and Table 2). The result showed that wind speed was the dominant climate factor influencing the trends of annual $\mathrm{ET}_{0}$. The contribution of wind speed to the changes in $\mathrm{ET}_{0}$ was $-4.12 \%$ for the whole study area. Among 57 stations, 48 of them were dominated by wind speed. Moreover, wind speed had negative contribution rate to the changes of $\mathrm{ET}_{0}$ for 41 stations due to the decreasing trend of wind speed (Fig. 7a). The maximal positive and negative contribution rates
Table 2 Sensitivity coefficients of $\mathrm{ET}_{0}$ for climate variables and their contributions

\begin{tabular}{lcccc}
\hline Climate variables & $\begin{array}{l}\text { Sensitivity } \\
\text { coefficient }\end{array}$ & $\begin{array}{l}\text { Sen's slope } \\
\text { estimator }\end{array}$ & $\begin{array}{l}\text { Relative } \\
\text { change (\%) }\end{array}$ & $\begin{array}{l}\text { Contribution } \\
\text { rate to the } \\
\text { changes in ET } \mathrm{ET}_{0}(\%)\end{array}$ \\
\hline Wind speed & 0.293 & -0.003 & -12.94 & -4.12 \\
Air temperature & 0.205 & 0.017 & 10.15 & 1.28 \\
Sunshine duration & 0.013 & -0.010 & -13.12 & -0.15 \\
Relative humidity & -0.037 & -0.029 & -1.94 & 0.11
\end{tabular}


occurred in Mianyang station of Sichuan (13.73\%) and Qianxi station of Guizhou $(-25.67 \%)$. This is same to the results from Yin et al. (2010), in which it was found that the decreasing trend of $\mathrm{ET}_{0}$ was primarily attributed to wind speed due to its significant decreasing trend and high sensitivity for China. Air temperature was the secondary climate factor for the changes of $\mathrm{ET}_{0}$, and its contribution was $1.28 \%$ for the whole study area. Mean air temperature was the dominated climate variable for nine stations, and had positive contribution for 51 stations due to their increasing trend in air temperature (Fig. 7b). The maximal positive and negative contribution rates of air temperature to $\mathrm{ET}_{0}$ were obtained respectively by Deqin station of Yunnan $(4.63 \%)$ and Guiyang station of Guizhou ( $-0.83 \%)$. The contribution rates of sunshine duration and relative humidity were less than $0.50 \%$ for all stations. In the study of Yin et al. (2010), however, sunshine duration was the secondary climate factor influencing the trends of annual $\mathrm{ET}_{0}$, which had a negative contribution $(-3.64 \%)$ for China as a whole, while its contribution was only $-0.15 \%$ for southwest China in this study. As Table 2 shows, the sensitivity coefficient for sunshine duration was small for southwest China (0.013) compared with the whole China (0.31) (Yin et al. 2010). For southwest China, air temperature had more important influences than sunshine duration. For relative humidity, its contribution for southwest China $(0.11 \%)$ also was less than that for China $(1.43 \%)$. Therefore, in annual scale, wind speed was the dominant climate variable for the change of $\mathrm{ET}_{0}$ in the study area, and the decreasing trends of annual wind speed for most stations were the main cause of the downward trend of
$\mathrm{ET}_{0}$. The positive contribution of air temperature to $\mathrm{ET}_{0}$ was offset by the influences of wind speed.

\section{Discussion}

From Fig. 3, it can be seen that the annual $\mathrm{ET}_{0}$ had an increasing trend after 1991, although it had a generally decreasing trend from 1960 to 2010 in southwest China. Cong et al. (2010) also reported that the increasing trend for $\mathrm{ET}_{0}$ appeared over China from 1956 to 2005. Liu et al. (2012) reported that $\mathrm{ET}_{0}$ had an increasing trend in China from 1993 to 2007. There were increasing trends for $\mathrm{ET}_{0}$ in other regions in China in recent years. For example, a slight increasing trend in $\mathrm{ET}_{0}$ was found over Yellow River basin in China from 1960 to 2007 (Liu et al. 2012). Liu and Zeng (2004) found, however, that pan evaporation had a decreasing trend over Yellow River basin from 1961 to 2000. The decreasing $\mathrm{ET}_{0}$ trend also was found in the Beijing-Tianjin Sand Source Control Project Region in China from 1959 to 2011 (Shan et al. 2015). Liu et al. (2011) reported that pan evaporation decreased in China from 1960 to 1991 while increased from 1992 to 2007. Much longer series of observation data are required to analyze how the phenomenon of "evaporation paradox" will change in future (Liu et al. 2012).

In this paper, the uncertainties of the contribution of climate variables to the changes of $\mathrm{ET}_{0}$ existed and came from the assumption where the climate variables were independent with each other (Liu et al. 2013). The interactions among the
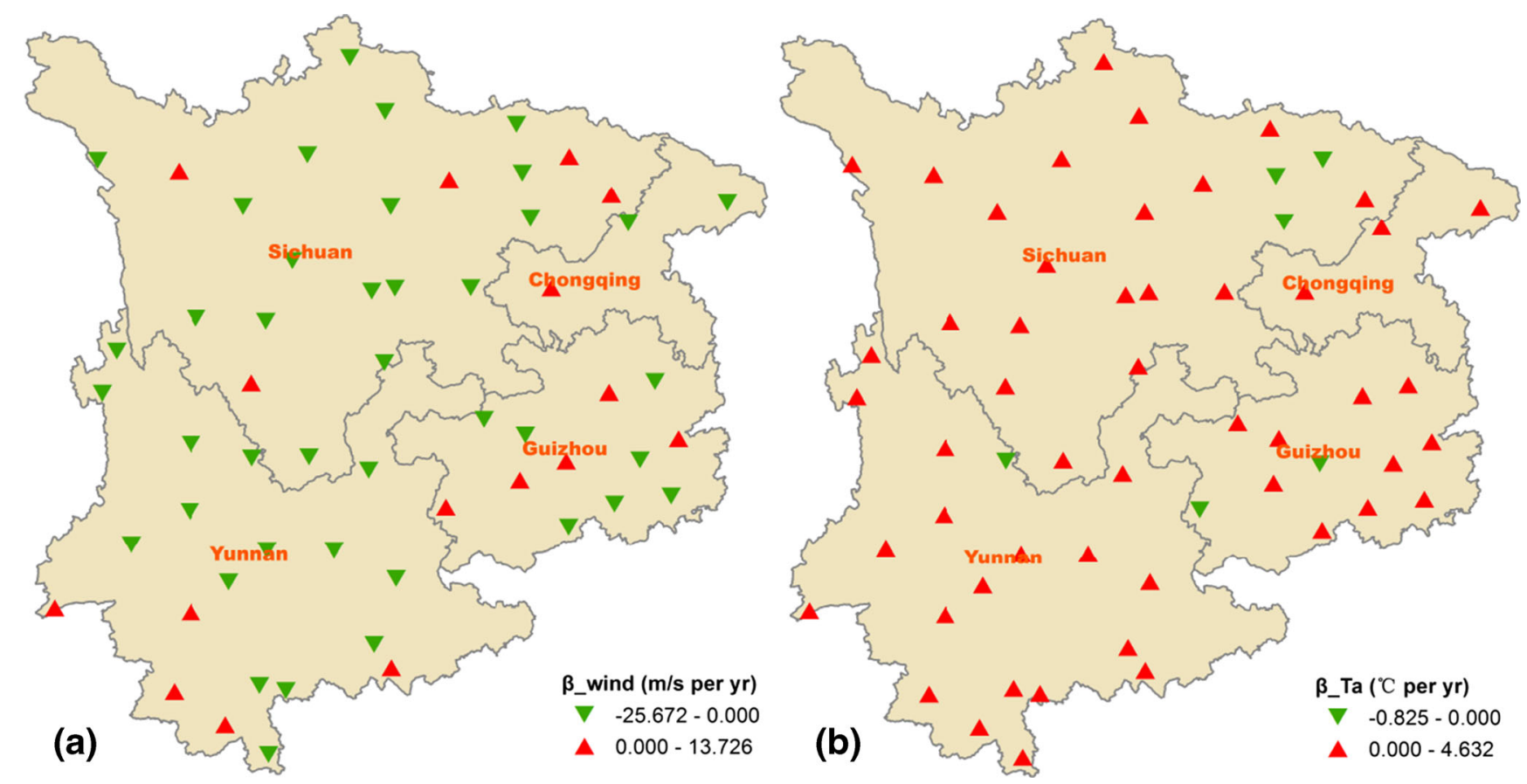

Fig. 7 Trend slopes $(\beta)$ of annual a wind speed and $\mathbf{b}$ air temperature from 1960 to 2010 
climate variables were neglected when the Eqs. (12)-(14) were used to analyze the contribution of climate variables. However, the assumption might be inaccurate and thus result in errors.

\section{Conclusions}

Spatial and temporal analyses of $\mathrm{ET}_{0}$ were conducted for the southwest region of China by using Mann-Kendall test, Sen's slope estimator, and sensitivity coefficient. The results showed that southwest China had a mean annual $\mathrm{ET}_{0}$ of $918.59 \mathrm{~mm} /$ year, and a decreasing trend in annual $\mathrm{ET}_{0}(\beta=-0.22 \mathrm{~mm} /$ year) from 1960-2010. In spatial distribution, southwest China had generally an increasing trend from northeast to southwest. Sensitivity analysis showed that relative humidity had negative influences on $\mathrm{ET}_{0}$, while the magnitude of its sensitivity coefficients was relatively lower. By contrast, $\mathrm{ET}_{0}$ had relatively higher sensitivity to wind speed and air temperature, and wind speed was the dominant climate variable for the changes of $\mathrm{ET}_{0}$. In this study, it can be concluded that the phenomenon of "evaporation paradox" existed in southwest China. The negative contribution of wind speed to the changes of $\mathrm{ET}_{0}$ offset the positive contribution of air temperature.

Acknowledgments This research was partially financed by the Natural Sciences Foundation of China (No. 41301021).

\section{References}

Allen RG, Pereira LS, Raes D, Smith M (1998) Crop evapotranspiration. Guidelines for computing crop water requirements. FAO, Rome, Irrig. Drain. Paper 56

Bandyopadhyay A, Bhadra A, Raghuwanshi NS, Singh R (2009) Temporal trends in estimates of reference evapotranspiration over India. J Hydrol Eng 14(5):508-515

Cong ZT, Yang DW, Ni GH (2009) Does evaporation paradox exist in China? Hydrol Earth Syst Sci 13:357-366

Cong ZT, Zhao JJ, Yang DW, Ni GH (2010) Understanding the hydrological trends of river basins in China. J Hydrol 388:350-356

Dinpashoh Y (2006) Study of reference crop evapotranspiration in I.R. of Iran. Agric Water Manag 84:123-129

Dinpashoh Y, Jhajharia D, Fakheri-Fard A, Singh VP, Kahya E (2011) Trends in reference crop evapotranspiration over Iran. J Hydrol 39:422-433

Gan TW (1998) Hydroclimatic trends and possible climatic warming in the Canadian prairies. Water Resour Res 34(11):3009-3015

Gao G, Chen DL, Ren GY, Chen Y, Liao YM (2006) Spatial and temporal variations and controlling factors of potential evapotranspiration in China: 1956-2000. J Geogr Sci 16:3-12

Hess TM (1998) Trends in reference evapotranspiration in the North East Arid Zone of Nigeria, 1961-1991. J Arid Environ 38:99-115

Jhajhariam D, Dinpashoh Y, Kahya E, Singh VP, Fakheri-Fard A (2011) Trends in reference evapotranspiration in the humid region of northeast India. Hydrol Process 26:421-435

Kendall MG (1975) Rank correlation methods. Griffin, London

Lawrimore JH, Peterson TC (2000) Pan evaporation trends in dry and humid regions of the United States. J Hydrometeorol 1:543-546
Liu CM, Zeng Y (2004) Changes of pan evaporation in the recent 40 years in the Yellow River Basin. Water Int 29(4):510-516

Liu Q, Yang Z, Xia X (2010) Trends for pan evaporation during 19592000 in China. Procedia Environ Sci 2:1934-1941

Liu XM, Luo YZ, Zhang D, Zhang MH, Liu CM (2011) Recent changes in pan-evaporation dynamics in China. Geophys Res Lett 38: (L13404) 4.doi:10.1029/2011GL047929

Liu CM, Zhang D, Liu XM, Zhao CS (2012) Spatial and temporal change in the potential evapotranspiration sensitivity to meteorological factors in China (1960-2007). J Geogr Sci 22(1):3-14

Liu XM, Zhang D, Luo YZ, Liu CM (2013) Spatial and temporal changes in aridity index in northwest China: 1960 to 2010. Theor Appl Climatol 112:307-316

Mann HB (1945) Nonparametric tests against trend. Econometrica 13: 245-259

McCuen RH (1974) A sensitivity and error analysis of procedures used for estimating evaporation. Water Resour Bull 10(3):486-498

Roderick ML, Farquhar GD (2002) The cause of decreased pan evaporation over the past 50 years. Science 298:1410-1411

Roderick ML, Farquhar GD (2004) Changes in Australian pan evaporation from 1970 to 2002. Int J Climatol 24:1077-1090

Sabziparvar AA, Tabari H, Aeini A, Ghafouri M (2010) Evaluation of class a pan coefficient models for estimation of reference crop evapotranspiration in cold-semi arid and warm arid climates. Water Resour Manag 24(5):909-920

Sen PK (1968) Estimates of the regression coefficient based on Kendall's tau. J Am Stat Assoc 63:1379-1389

Shan N, Shi ZJ, Yang XH, Gao JX, Cai DW (2015) Spatiotemporal trends of reference evapotranspiration and its driving factors in the Beijing-Tianjin Sand Source Control Project Region, China. Agric For Meteorol 200:322-333

Tabari H, Aeini A, Talaee PH, Some'e BS (2012) Spatial distribution and temporal variation of reference evapotranspiration in arid and semiarid regions of Iran. Hydrol Process 26:500-512

Talaee PH, Some'e BS, Ardakani SS (2014) Time trend and change point of reference evapotranspiration over Iran. Theor Appl Climatol 116: 639-647

Thomas A (2000) Spatial and temporal characteristics of potential evapotranspiration trends over China. Int J Climatol 20:381-396

Wang W, Wang WJ, Li JS, Wu H, Xu C, Liu T (2010) The impact of sustained drought on vegetation ecosystem in Southwest China based on remote sensing. Procedia Environ Sci 2:1679-1691

Wang WG, Shao QX, Peng SZ, Xing WQ, Yang T, Luo YF, Yong B, Xu JZ (2012) Reference evapotranspiration change and the causes across the Yellow River Basin during 1957-2008 and their spatial and seasonal differences. Water Resour Res 48, W05530. doi:10. 1029/2011WR010724

Xu CY, Gong LB, Jiang T, Chen DL, Singh VP (2006) Analysis of spatial distribution and temporal trend of reference evapotranspiration and pan evaporation in Changjiang (Yangtze River) catchment. J Hydrol 327:81-93

Ye XC, Li XH, Liu J, Xu CY, Zhang Q (2014) Variation of reference evapotranspiration and its contributing climatic factors in the Poyang Lake catchment, China. Hydrol Process 28:6151-6162

Yin YH, Wu SH, Chen G, Dai EF (2010) Attribution analyses of potential evapotranspiration changes in China since the 1960s. Theor Appl Climatol 101:19-28

Zhao YF, Zou XQ, Zhang JX, Cao LG, Xu XWH, Zhang X, Chen YY (2014) Spatio-temporal variation of reference evapotranspiration and aridity index in the Loess Plateau Region of China, during 1961-2012. Quat Int 349:196-206

Zuo DP, Xu ZX, Yang H, Liu XC (2012) Spatiotemporal variations and abrupt changes of potential evapotranspiration and its sensitivity to key meteorological variables in the Wei River basin, China. Hydrol Process 26:1149-1160 